\title{
Volatility Spillovers from Australia's major trading partners across the GFC
}

Complutense

de Análisis

Económico

\section{David E. Allen}

School of Mathematics and Statistics, the University of Sydney, and Center for Applied Financial Studies, University of South Australia

\section{Michael McAleer}

Econometric Institute, Erasmus School of Economics, Erasmus University Rotterdam, Tinbergen Institute, The Netherlands, Department of Quantitative Finance, College of Technology Management, National Tsing HuaUniversity Hsinchu, Taiwan, Distinguished Chair Professor, College of Management, National Chung Hsing University, Taichung, Taiwan, Department of Quantitative Economics, Complutense University of Madrid, Spain,

\author{
Abhay K. Singh \\ School of Accounting, Finance and Economics, Edith Cowan University, Australia
}

\begin{abstract}
This paper features an analysis of volatility spillover effects from Australia's major trading partners, namely, China, Japan, Korea and the United States, for a period running from 12th September 2002 to 9th September 2012. This captures the impact of the Global Financial Crisis (GFC). These markets are represented by the following major indices: The Shanghai composite and the Hangseng. (In the case of China, as both China and Hong Kong appear in Australian trade statistics), the S\&P500 index, the Nikkei225 and the Kospi index. We apply the Diebold and Yilmaz (2009) Spillover Index, constructed in a VAR framework, to assess spillovers across these markets in returns and in volatilities. The analysis con $\square \mathrm{rms}$ that the US and Hong Kong markets have the greatest in $\square$ uence on the Australian one. We then move to a GARCH framework to apply further analysis and apply a tri-variate Cholesky-GARCH model to explore the e $\square$ ects from the US and Chinese market, as represented by the Hang Seng Index.
\end{abstract}

Keywords: Volatility Spillover Index, VAR analysis, Variance Decomposition, Cholesky-GARCH JL Classification G11, C02.

\section{Working Paper no 1426 August, 2014}

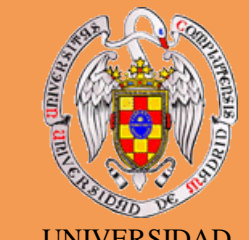

UNIVERSIDAD

COMPLUTENSE MADRID 


\title{
Volatility Spillovers from Australia's major trading partners across the GFC
}

\author{
David E. Allen ${ }^{\mathrm{a}, *}$, Michael McAleer ${ }^{\mathrm{b}}$, Robert J. Powell ${ }^{\mathrm{c}}$, and Abhay K. Singh ${ }^{\mathrm{c}}$ \\ ${ }^{a}$ School of Mathematics and Statistics, the University of Sydney, and Center for Applied Financial Studies, \\ University of South Australia \\ ${ }^{b}$ Econometric Institute, Erasmus School of Economics, Erasmus University Rotterdam, Tinbergen Institute, The \\ Netherlands, Department of Quantitative Finance, College of Technology Management, National Tsing Hua \\ University Hsinchu, Taiwan, Distinguished Chair Professor, College of Management, National Chung Hsing \\ University, Taichung, Taiwan, Department of Quantitative Economics, Complutense University of Madrid, Spain, \\ ${ }^{c}$ School of Accounting, Finance and Economics, Edith Cowan University, Australia
}

\begin{abstract}
This paper features an analysis of volatility spillover effects from Australia's major trading partners, namely, China, Japan, Korea and the United States, for a period running from 12th September 2002 to 9 th September 2012. This captures the impact of the Global Financial Crisis (GFC). These markets are represented by the following major indices: The Shanghai composite and the Hangseng. (in the case of China, as both China and Hong Kong appear in Australian trade statistics), the S\&P500 index, the Nikkei225 and the Kospi index. We apply the Diebold and Yilmaz (2009) Spillover Index, constructed in a VAR framework, to assess spillovers across these markets in returns and in volatilities. The analysis confirms that the US and Hong Kong markets have the greatest influence on the Australian one. We then move to a GARCH framework to apply further analysis and apply a tri-variate Cholesky-GARCH model to explore the effects from the US and Chinese market, as represented by the Hang Seng Index.
\end{abstract}

Keywords: Volatility Spillover Index, VAR analysis, Variance Decomposition, Cholesky-GARCH

\section{Introduction}

The Global Financial Crisis (GFC) had a major impact on the world's financial markets. This paper examines whether there is evidence of spillovers of volatility from Australia's main trading partners, namely, China, Japan, Korea and the United States, for a period running from 12th September 2002 to 9th September 2012, to the Australia stock market. The paper features an application of Diebold and Yilmaz's (2009) Spillover Index model, to assess the impact of the GFC on spillovers to the Australian market, on both returns and volatility series. This is followed by an application of a Cholesky-GARCH trivariate model to directly model the influence of both the US

*Corresponding author. Acknowledgements: For financial support, the first author acknowledges the Australian Research Council, and the third author is most grateful to the Australian Research Council, National Science Council, Taiwan, and the Japan Society for the Promotion of Science.We are grateful to the anonymous reviewers for helpful comments.

Email address: profallen2007@gmail.com (David E. Allen) 
and Chinese markets, as represented by Hong Kong and the Hang Seng Index, not Shanghai and the Shanghai Composite Index, because the Spillover Index analysis, conducted in a VAR and variance decomposition framework, reveals that these two markets are the most influential on the Australian market, even though they are currently ranked fourth and fifth, in importance, as trading partners, (see Figure 2).

The recent GFC crisis commenced in 2007 and continued through to the European sovereign debt crisis. Alan Greenspan (2010) took the view that: "The bubble started to unravel in the Summer of 2007. But unlike the debt-like deflation of the earlier dotcom boom, heavy leveraging set off serial defaults, culminating in what is likely to be viewed as the most virulent financial crisis ever. The major failure of both private risk management and official regulation was to significantly misjudge the size of tail risks that were exposed in the aftermath of the Lehman default."

The U.S. subprime mortgage and credit crisis was characterized by turbulence that spread from subprime mortgage markets to credit markets more generally, and then to short-term interbank markets as liquidity evaporated, particularly in structured credit then on to stock markets globally.

Gorton (2010) suggested that the GFC was not particularly different from previous crises except that, prior to 2007, most investors had never heard of the markets that were involved. Concepts such as subprime mortgages, asset-backed commercial paper conduits, structured investment vehicles, credit derivatives, securitization, or repo markets were not common knowledge. Gorton (2010) suggests that the securitized banking system is a real banking system that is still vulnerable to a panic. He argues that the crisis, beginning in August 2007, can best be understood as a wholesale panic involving institutions, where large financial firms, "ran" on other financial firms, making the system insolvent.

Fidrmuc and Korhonen (2010), analyze the transmission of global financial crisis to business cycles in China and India using GDP data and dynamic correlation analysis. They report a significant link between trade ties and dynamic correlations of GDP growth rates in emerging Asian countries and OECD countries. Cheng, and Glascock (2005), examine the linkages among three Greater China Economic Area (GCEA) stock markets, including Mainland China, Hong Kong, and Taiwan, and two developed markets, Japan and the United States. They find that a random walk model is outpredicted by an autoregressive GARCH model, and an ARIMA model, in all three GCEA markets, and that there is no evidence of cointegration between the markets. Chung et al. (2010), examine the informational role of the TED spread as perceived credit risk. They apply a Vector Autoregressive (VAR) model, Granger causality tests, cointegrating Vector Error Correction Model (VECM), to analyse the leadership of the US market with respect to UK, Hong Kong, Japan, Australia, Russia and China markets, during the crisis, and find evidence of increased interdependence during the crisis. They suggest that the impact of orthogonalized shocks from the US market, on other global markets, increases by at least two times during the crisis, and that of the TED spread, even more so.

Didier et al. (2012), examine the determinants of comovement in stock market returns during the 2007-2008 crisis. They explore the influence of the United States (US), via analysis of the factors driving the comovement between US stock market returns and stock market returns in 83 countries. Their analysis distinguishes between the period before and after the collapse of Lehman Brothers, and their findings indicate that comovement was driven largely by financial linkages. Dooley and Hutchison (2009) explore the transmission of the crisis to the emerging markets. They suggest that whilst initially these markets were largely shielded from the deleterious effects on world trade flows, they subsequently had strong effects after the Lehmann bankruptcy. Huang et al. (2000), apply similar causality and cointegration relationships among the stock markets of the United States, 
Japan and the South China Growth Triangle (SCGT) region, and report no evidence of cointegration amongst these markets, save the Chinese ones of Shanghai and Shenzen. Kotkatvuori-Örnberg et al. (2013), explore stock market correlations during the financial crisis across 50 equity markets. They measure the value of covariance information using an the augmented DCC model, and show that by taking into account the change in the level of variance in high volatility periods, the estimates of the conditional covariance are more efficient in capturing the dynamics of the stock market's variance. Min and Hwang (2012), also use dynamic correlation analysis of US financial crisis to explore contagion from the US across four OECD countries. They find a process of increasing correlations (contagion), in the first phase of the US financial crisis, and an additional increase of correlations (herding), during the second phase of the US financial crisis, for the UK, Australia and Switzerland. Mun and Brooks (2012) explore the roles of news and volatility in stock market correlations during the global financial crisis. Their results show that the majority of the correlations are more strongly explained by volatility than news. Yeh and Lee (2000), analyse the interaction and volatility asymmetry of unexpected returns in the greater China stock markets. They suggest that results, of a near vector autoregressions (VAR) model, reveal that the Hong Kong stock market plays an influential role as a regional force amongst the Taiwan, Shanghai, and Shenzhen B-share stock markets.

There are a number of common themes in this literature. The global studies that include the US suggest that it has a major influence in the transmission of shocks to both developed and undeveloped markets. The econometric methods, used in these studies, range across a number of time series econometrics techniques including cointegration, VAR models, and applications of models nested in the GARCH framework, including multivariate models such as DCC.

However, also germane to the approach adopted in the current paper, is a recent study by Diebold and Yilmaz (2009), who formulate and examine precise and separate measures of return spillovers and volatility spillovers. They base their measurement of return and volatility spillovers on vector autoregressive (VAR) models, in the broad tradition of Engle et al. (1990). They focus on variance decompositions, which they argue are well understood and widely calculated. They use them to aggregate spillover effects across markets, which permits the distillation of a wealth of information into a single spillover measure. We adopt their approach, plus a tri-variate CholeskyGARCH model which permits an analysis of the relationships with those markets with the greatest influence on the Australian market, as revealed by the application of their Spillover Index.

Our analysis is therefore focussed on the relationship with Australia's main trading partners, China, Japan, the United States, Hong Kong and Korea, given that both trade flows and attached information flows are likely to have an economic impact, and be reflected in the behaviour of equity indices (see for example, Evans and Hnatkovska (2014)).

In this paper we focus on how the GFC impacted on volatility spillovers across the world to the Australian equity market. Even though the Australian financial markets were spared the major effects of the GFC, in terms of distress to major financial institutions, the Australian financial market was still impacted by these major global events. The degree to which the Australian market is influenced by extreme events in the US, has implications for portfolio optimization by Australian investors and fund managers alike, and effects the degree to which it is possible to hedge risk during times of financial turbulence. We examine how both return and volatility spillovers and correlations changed, between the Australian market and the US during the financial crisis. We focus on the impact of the Chinese market in our analyses, given that its is Australia's main trading partner, together with the influence of the US market, given that this it has consistently been shown to have the greatest impact on other global markets, in the prior studies mentioned, even though it is only 
Australia's fourth most significant trading partner.

\section{Research Method}

\subsection{Data set and econometric models}

We wanted to make sure that we captured the relationships with Australia's main trading partners. Figure 1 below depicts Australia's top ten partners in trades in goods and services in 2013 taken from the DFAT top ten list.

Figure 1: Top 10 partners in trade in goods and services 2013

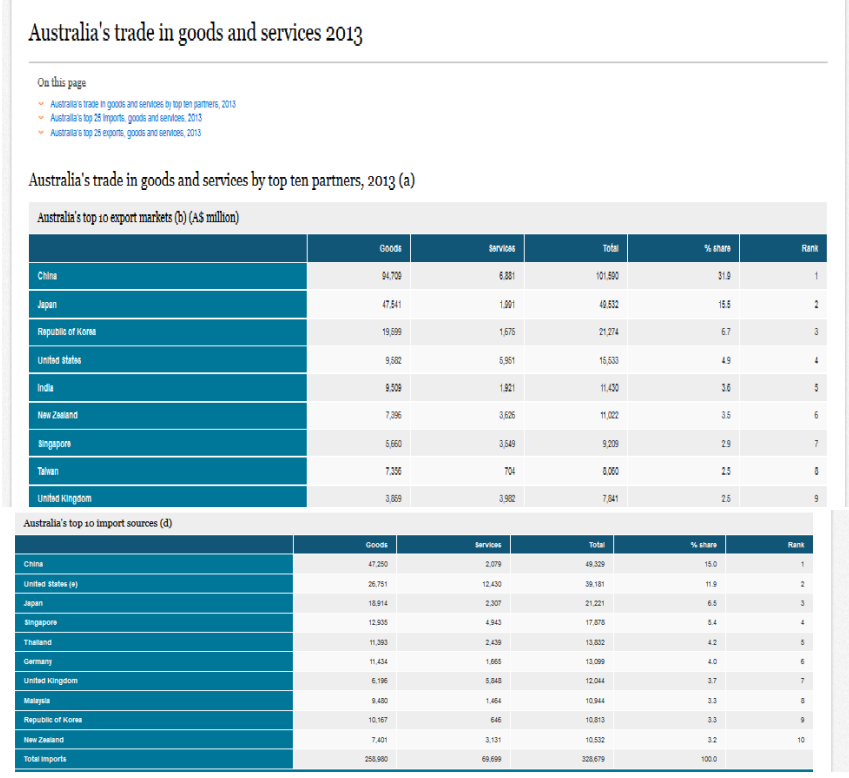

Source: http://dfat.gov.au/publications/tgs/index.html

Figure 2 depicts the trend in trade in goods and services from 2001 to 2013, with exports in the top half of the diagram and imports in the bottom. It can be seen that trade with China has become ever more important overtaking trade with Japan as the major trading partner in 2008-2009. Trade with Korea, particularly in imports, has increased in importance since 2004 when it overtook trade with the US in relative importance. The fifth most important trading partner is Hong Kong whose relative importance has not changed over this period. For the purposes of our analysis we have concentrated on the top six trading partners, in terms of exports, as this reflects our major trading partners and has implications for export income. 
Figure 2: Australia's major trading partners 2001-2013

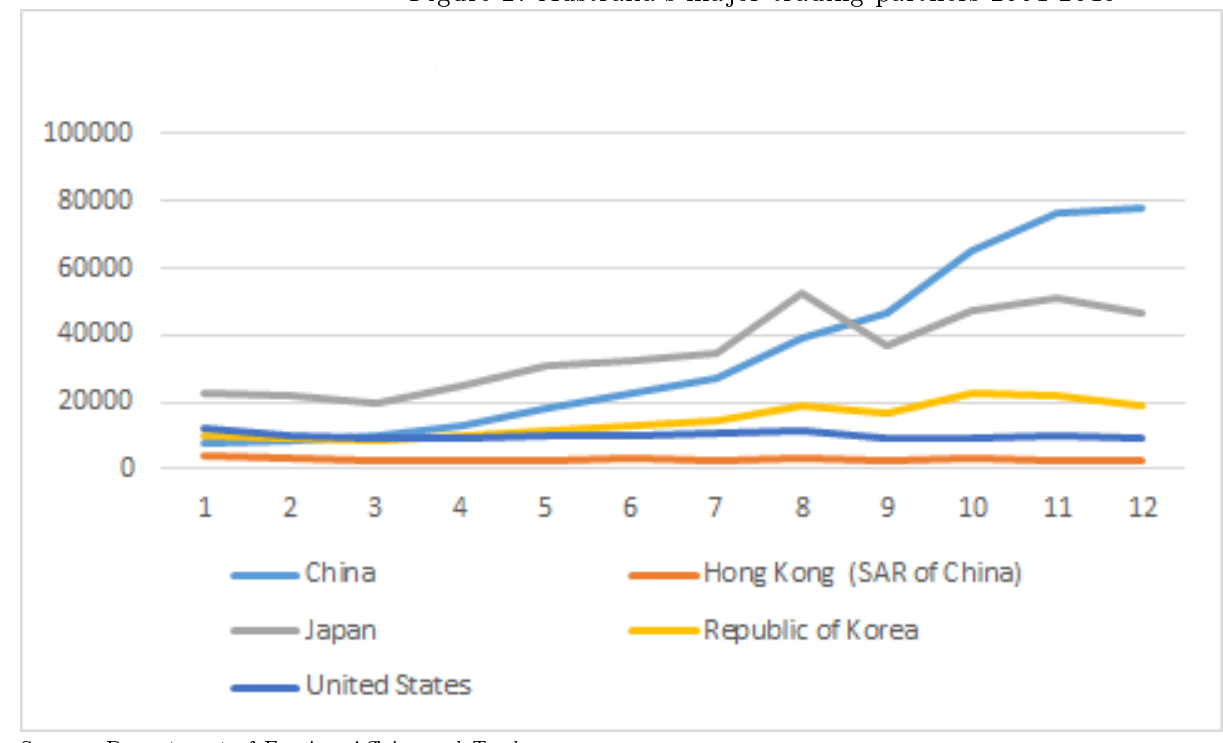

Source: Department of Foreign Affairs and Trade.

We took a series of major stock market indices representing these six countries; namely the Shanghai Stock Exchange (SSE) composite index, the Hang Seng Index, the Australian All Ordinaries Index, the Nikkei 225 Index, the S\&P500 Index and the Kospi Index. The data set includes daily data for each index from 1st January 2004, until 30th June 2014. The indexes are total market indexes, based on market capitalizations, and are taken from Datastream standardised in US dollar terms. Daily returns are calculated as follows:

$$
y_{i t}=\ln \left(p_{i t}\right)-\ln \left(p_{i t-1}\right)
$$

The data sets used are shown in Table 1. (We lagged the US S\&P 500 index returns by one day to make them more comparable in time with the Australian and other Asian series).

\begin{tabular}{|c||c|}
\hline Country & Index \\
\hline \hline USA & S\&P500 \\
\hline \hline AUSTRALIA & All Ordinaries \\
\hline CHINA & Hang Seng \\
\hline CHINA & Shanghai Stock Exchange Composite \\
\hline JAPAN & Nikkei 225 \\
\hline KOREA & Kospi \\
\hline
\end{tabular}

Table 1: List of countries and indices

There are a variety of models that could be used to test for the existence of time-varying volatility, and for spillover effects in returns and volatility across markets. 
One approach is to use a time series Vector Autoregressive (VAR) framework. This was recently formalised by Diebold and Yilmaz (2009) and Diebold and Yilmaz (2012), who modelled spillovers using VAR models and variance decompositions. They constructed a spillover index based both on return spillovers and volatility spillovers. Their approach is initially attractive for our purposes, because it enables us to see which of the six markets considered makes the largest contribution to the spillover of returns and volatilities into the Australian market. We commence with an application of their model which enables us to determine which of Australia's trading partners contributes most to equity shocks. Once we have used their model as an initial filter we then proceed to apply models within a GARCH framework.

The returns spillover index uses our basic index data. For the volatility based estimates we departed from the procedure used by Diebold and Yilmaz (2009), which used weekly ranged-based estimates to assess volatility. We preferred to use realised volatility metrics. We employ the the Oxford-Man Institute of Quantitative Finance's "realised library" which contains daily nonparametric measures of how the volatility of financial assets or indexes were in the past. Each day's volatility measure depends solely on financial data from that day. We choose the series constructed by sampling at 10 minute intervals within the day. Data is available for download on the OxfordMan website (http://realized.oxford-man.ox.ac.uk/), and we took daily estimates for all our markets which were available for the full sample period, apart from the Shanghai Stock Exchange composite index which is not covered. The raw high frequency data is taken from Reuters DataScope Tick History database. These RV estimates were then utilised for the spillover index analysis of volatility.

\subsection{The Diebold and Yilmaz (2009) Spillover Index}

Diebold and Yilmaz (2009) suggest that the advantage of the adoption of a VAR framework and the use of variance decompositions is that they permit the aggregation of spillover effects across markets, distilling a wealth of information into a single spillover measure. This suits our current purposes and permits an examination of the relative contributions to spillovers made by the six markets in our sample. They proceed to develop their measure by taking each asset $i$, and adding the shares of its forecast error variance coming from shocks to asset $j$, for all $j \neq i$, all in the context of an $n$ variable VAR. They then sum these error variances across all $i=1, \ldots, N$. If we take the case of a covariance stationary, first-order, two variable VAR, we have;

$$
x_{t}=\Phi x_{t-1}+\varepsilon_{t}
$$

where $x_{t}=\left(x_{1 t}, x_{2 t}\right)$ and $\Phi$ is a $2 \times 2$ parameter matrix. In the empirical analysis which follows, $x$ will be either a vector of index returns or a vector of index volatilities. The moving average representation of the VAR can be written, given the existence of covariance stationarity, as;

$$
x_{t}=\Theta(L) \varepsilon_{t}
$$

where $\Theta(L)=(1-\Phi L)^{-1}$. The moving average representation can be conveniently written as;

$$
x_{t}=A(L) u_{t}
$$

where $A(L)=\Theta(L) Q_{t}^{-1}, u_{t}=Q_{t} \varepsilon_{t}, E\left(u_{t} u_{t}^{\prime}\right)=I$, and $Q_{t}^{-1}$ is the unique lower-triangular Choleski factor of the covariance matrix of $\varepsilon_{t}$.

Diebold and Yilmaz (2009) then proceed to consider the optimal 1 step ahead forecast, given by; 


$$
x_{t+1, t}=\Phi x_{t},
$$

with the corresponding one-step ahead error vector

$$
e_{t+1, t}=x_{t+1}-x_{t+1, t}=A_{0} u_{t+1}=\left[\begin{array}{ll}
a_{0,11} & a_{0,12} \\
a_{0,21} & a_{0,22}
\end{array}\right]\left[\begin{array}{l}
u_{1, t+1} \\
u_{2, t+1}
\end{array}\right]
$$

which has the covariance matrix;

$$
E\left(e_{t+1, t} e_{t+1, t}^{\prime}\right)=A_{0} A_{0}^{\prime}
$$

This suggests that the variance of a one-step ahead error in forecasting $x_{1, t}$ is $a_{0,11}^{2}+a_{0,12}^{2}$ and the variance of the one-step ahead error in forecasting $x_{2, t}$ is $a_{0,21}^{2}+a_{0,22}^{2}$. Diebold and Yalmiz (2009) demonstrate that it is possible to to split the forecast error variances of each variable into components attributable to the various system shocks. In this two variable system it is possible to distinguish between shocks to the variable itself $x_{i}$ and shocks to the other variable $x_{j}$, for $i, j=1,2, i \neq j$.

Diebold and Yalmaz calculate a spillover index in the two variable case as;

$$
S=\frac{a_{0,12}^{2}+a_{2,1}^{2}}{\operatorname{trace}\left(A_{0} A_{0}^{\prime}\right.} \times 100
$$

They then generalise the measure to take into account multiple securities and multiple periods as shown below:

$$
S=\frac{\sum_{h=0}^{H-1} \sum_{\substack{i, j=1 \\ i \neq j}}^{N} a_{h, i j}^{2}}{\sum_{h=0}^{H-1} \operatorname{trace}\left(A_{h} A_{h}^{\prime}\right)}
$$

Diebold and Yilmaz (2012) extend their approach to include a generalized vector autoregressive framework in which forecast-error variance decompositions are invariant to variable ordering. We also apply this metric, but will not develop their model here, and refer the interested reader to their original discussion of the model (See Diebold and Yilmaz (2012)).

In the empirical work that follows in the next section, we will use second-order six variable VARs with 10 step-ahead forecasts, and apply the two variants of their model, to both return and variance series. The results suggest that the US market dominates spillovers, with the Hong Kong market the second most important from those considered. We use this finding in the subsequent GARCH analyses.

\subsection{GARCH models}

Manganelli and Engle (2001), claim that the main differences between the variations in the approaches, adopted in this class of models, is how they deal with the return distribution, and they proceed to classify these models into three distinct groups:

- Parametric, such as RiskMetrics and GARCH;

- Nonparametric, such as Historical simulation and the Hybrid Model;

- Semiparametric, such as CAViaR, Extreme Value Theory, and Quasi-Maximum Likelihood GARCH. 
Engle (1982), developed the Autoregressive Conditional Heteroskedasticity (ARCH) model, that incorporates all past error terms. It was generalised to GARCH by Bollerslev (1986), to include lagged term conditional volatility. In other words, GARCH predicts that the best indicator of future variance is the weighted average of long-run variance, the predicted variance for the current period, and any new information in this period, as captured by the squared residuals (Engle, (2001)).

The framework is developed as follows: consider a time series $y_{t}=E_{t-1}\left(y_{t}\right)+\varepsilon_{t}$, where $E_{t-1}\left(y_{t}\right)$ is the conditional expectation of $y_{t}$ at time $t-1$ and $\varepsilon_{t}$ is the error term. The basic GARCH model has the following specification:

$$
\begin{gathered}
\varepsilon_{t}=\sqrt{h_{t} \eta_{t}}, \quad \eta_{t} \sim N(0,1) \\
h_{t}=\omega+\sum_{j=1}^{p} \alpha \varepsilon_{t-j}^{2}+\sum_{j=1}^{q} \beta_{j} h_{t-j}
\end{gathered}
$$

in which $\omega>0, \alpha_{j} \geq 0$ and $\beta_{j} \geq 0$, are sufficient conditions to ensure a positive conditional variance, $h_{t} \geq 0$. The ARCH effect is captured by the parameter $\alpha_{j}$, which represents the short run persistence of shocks to returns. $\beta_{j}$ captures the GARCH effect, and $\alpha_{j}+\beta_{j}$ measures the persistence of the impact of shocks to returns to long-run persistence. A GARCH( 1,1$)$ process is weakly stationary if $\alpha_{j}+\beta_{j} \leq 1$.

Ling and McAleer (2003), and Harris, Stoja and Tucker (2007), claim that the GARCH model is "perhaps the most widely used approach to modeling the conditional covariance matrix of returns". Engle (2001), states it has been successful, even in its simplest form, in predicting conditional variance. The main advantage of this model is that it allows; "a complete characterization of the distribution of returns and there may be space for improving their performance by avoiding the normality assumption" (Manganelli and Engle, (2001, p.9)). However, Engle (2001), Nelson (1991), Zhang and Li (2008), and Harris, Stoja and Tucker (2007), also outline some of the disadvantages of the GARCH model as follows; GARCH can be computationally burdensome and can involve simultaneous estimation of a large number of parameters. GARCH tends to underestimate risk, (when applied to Value-at-Risk, VaR), as the normality assumption of the standardized residual does not always hold with the behaviour of financial returns. The specification of the conditional variance equation and the distribution used to construct the log-likelihood may be incorrect. GARCH rules out, by assumption, the negative leverage relationship between current returns and future volatilities, despite some empirical evidence to the contrary.

GARCH assumes that the magnitude of excess returns determines future volatility, but not the sign (positive or negative returns), as it is a symmetric model. This is a significant problem, as research by Nelson (1991), and Glosten, Jagannathan and Runkle (GJR) (1993), shows that asset returns and volatility do not react in the same way for negative information, or 'bad news', as they do for positive information, or 'good news', of equal magnitude.

In order to deal with these problems, a large number of variations on the basic GARCH model have been created, each one dealing with different issues. Bollerslev (1990) developed a multivariate GARCH (MGARCH) model that asumes Constant Conditional Correlation (CCC). In other words, it assumes the independence of asset returns' conditional variance. Multivariate GARCH (MGARCH) models have recently been used widely in risk management and sensitivity analysis.

Bauwens, Laurent and Rombouts (2003), suggest that the most appropriate use of multivariate GARCH models is to model the volatility of one market with regard to the co-volatility of other markets. In other words, these models are used to see if the volatility of one market leads the 
volatility of other markets (the 'Spillover Effect'). They also assert that these models can be used to model the tangible effects of volatility, such as the impact of changes in volatility on exports and output growth rates. Bauwens, Laurent and Rombouts (2003), suggest that these models are also efficient in determining whether volatility is transmitted between markets, through the conditional variance (directly), or conditional covariances (indirectly), whether shocks to one market increase the volatility of another market, and the magnitude of that increase, and whether negative information has the same impact as positive information of equal magnitude.

Nelson (1991) developed the Exponential GARCH (EGARCH) model. This model uses logarithms to ensure that the conditional variance is non-negative, and captures both the size and sign effects of shocks, capturing the effect of asymmetric returns on conditional volatility. This model was the first to capture the asymmetric impact of information. A second model, which is computationally less burdensome then Nelson's EGARCH, is the Glosten, Jagannathan and Runkle (GJR) model (1993). They found significant evidence of seasonal effects on the conditional variance in the NYSE Value-Weighted Index. Engle and Ng (1993), claim that the GJR forecasts of volatility are more accurate than those of the EGARCH model. Necessary and sufficient conditions for the second

order stationarity of the GARCH model are $\sum_{i=1}^{r} \alpha_{i}+\sum_{i=1}^{s} \beta_{i}<1$, as demonstrated by Bollerslev (1986). The necessary and sufficient conditions for the GJR $(1,1)$ model were developed by Ling and McAleer (2003), who showed that $E\left(\varepsilon_{t}^{2}\right)<\infty$ if $\alpha_{1}+\frac{\gamma_{1}}{2}+\beta_{1}<1$. Subsequently, McAleer et al. (2007) demonstrated the log-moment condition for the GJR(1,1) model, which is sufficient for consistency and asymptotic normality of the QMLE, namely $E\left(\log \left(\alpha_{1}+\gamma_{1} I\left(\eta_{t}\right) \eta_{t}^{2}+\beta_{1}\right)\right)<0$.

\subsection{Multivariate conditional volatility models}

There are a wide variety of specifications available for multivariate conditional volatility modelling. We originally adopted a bi-mean equation to model the conditional mean in the individual markets plus an ARMA model to capture volatility spillovers from the US across the other markets considered. We commenced by adopting a vector ARMA structure with exogenous variables for the conditional mean equation $\mu_{t}$ as shown below:

$$
u_{t}=\Upsilon x_{t}+\sum_{i=1}^{p} \Phi_{i} r_{t-i}-\sum_{i=1}^{q} \Theta_{i} a_{t-i}
$$

where $x_{t}$ denotes an m-dimensional matrix of explanatory variables, $\Upsilon$ is a $k \times m$ matrix and $p$ and $q$ are nonnegative integers.

We considered univariate models of single assets in the previous section. However, in finance the behaviour of portfolios of assets is of primary interest. If we want to forecast the returns of portfolios of assets, we must consider the correlations and covariances between individual assets. A common approach adopted to the specification of multivariate conditional means and conditional variances of returns is as follows:

$$
\begin{gathered}
y_{t}=E\left(y_{t} \mid F_{t-1}\right)+\varepsilon_{t} \\
\varepsilon_{t}=D_{t} \eta_{t}
\end{gathered}
$$

In (5) above, $y_{t}=\left(y_{1 t}, \ldots ., y_{m t}\right)^{\prime}, \quad \eta_{t}=\left(\eta_{i t}, \ldots \ldots, \eta_{m t}\right)^{\prime}$, a sequence of (i.i.d) random vectors, $F_{t}$ is a vector of past information available at time $t, D_{t}=\operatorname{diag}\left(h_{1}^{1 / 2}, \ldots \ldots ., h_{m}^{1 / 2}\right), m$ is the 
number of returns, and $t=1, \ldots, n$. (For a full exposition, see Li, Ling and McAleer (2003), McAleer (2005) and Bauwens et al (2003). The Bollerslev (1990) constant conditional correlation (CCC) model assumes that the conditional variance of each return, $h_{i t}, i=1, \ldots, m$, follows a univariate GARCH process:

$$
h_{i t}=\omega+\sum_{j=1}^{r} \alpha_{i j} \varepsilon_{i, t-j}^{2}+\sum_{j=1}^{s} \beta_{i j} h_{i . t-j}
$$

In (6) above, $\alpha_{i j}$ represents the ARCH effect, or the short run persistence of shocks to return $i$, and $\beta_{i j}$ captures the GARCH effect; the impact of shocks to return $i$ on long run persistence, given by:

$$
\sum_{j=1}^{r} \alpha_{i j}+\sum_{j=1}^{s} \beta_{i j} .
$$

It follows that the conditional correlation matrix of CCC is $\Gamma=E\left(\eta_{t} \eta_{t}^{\prime} \mid F_{t-1}\right)=E\left(\eta_{t} \eta_{t}^{\prime}\right)$, where $\Gamma=\left\{\rho_{i t}\right\}$ for $i, j=1, \ldots, m$. From $(5), \varepsilon_{t} \epsilon_{t}^{\prime}=D_{t} \eta_{t} \eta_{t}^{\prime} D_{t}, \quad D_{t}=\left(\operatorname{diag} Q_{t}\right)^{1 / 2}$, and $E\left(\varepsilon_{t} \varepsilon_{t}^{\prime} \mid F_{t-1}\right)=$ $Q_{t}=D_{t} \Gamma D_{t}$, where $Q_{t}$ is the conditional covariance matrix, $\Gamma=D_{t}^{-1} Q_{t} D_{t}^{-1}$ is the conditional correlation matrix and the individual conditional correlation coefficients are calculated from the standardised residuals in equations (5) and (6). This means that there is no multivariate estimation required in $\mathrm{CCC}$, which involves $m$ univariate GARCH models, except in the case of the calculation of conditional correlations.

We initially attempted to apply variants of the VARMA-GARCH models but had difficulty obtaining convergence and sensible results. We then decided to utilise Cholesky-GARCH decompositions, in which the analysis is done sequentially, and avoided the problems with convergence using this approach. This could also be justified because the Spillover Index analysis indicated the relative importance of shock contributions from the different markets.

\subsection{Model specifications}

Our goal in this paper is to model spillover effects, and we adopt a variety of parametric techniques. We commenced our analysis with Diebold and Yilmaz (2009) spillover index applying a VAR approach. Then we moved to a GARCH modelling framework with the adoption of multivariate models. Problems encountered with variants of the VARMA-GARCH models lead to the use of a model in which we could order the choice of markets. We explore the relationship between Australia and the other two most important markets contributing spillovers, using a Cholesky-GARCH model for the empirical analysis. (See the discussion in Tsay (2005) and Dellaportos and Pourahmadi (2012)). (We used modified versions of Tsay's (2005) Rats code and Doans (2011) Rats code to undertake the analysis).

In the context of measuring asymmetric shocks and spillover effects, we proceed as follows:

1. First we apply the Diebold Yilmaz (2009) and (2012) variants of the Spillover Index to model spillovers in both returns and volatilities.

2. This analysis reveals which market indices have the greatest impact in terms of spillovers of returns and volatilities into the Australian market. We use this information to construct the appropriate multivariate GARCH model.

3. We utilise Cholesky decompositions to build a higher dimensional GARCH model. We write the vector return series as $r_{t}=\mu_{t}+\alpha_{t}$ and use a vector AR model for modelling the behaviour of the mean. We then proceed in stages: 
- First we build a univariate GARCH model of the US S\&P500 index series.

- Then we add the Australian S\&P200 index series to the system, perform an orthogonal transformation on the shock process of the Australian return series, and build a bivariate volatility model for the system. The parameter estimates for the US model developed in step one can be used as staring values in the bivariate estimation.

- Given that Australia is a major trading partner of China it is possible that links with the Chinese markets also impact upon volatility. A third component of the system is a Chinese index, in this case the Shang Hai Stock Exchange index. The shock process for this third return series is subjected to an orthogonal transformation and a three-dimensional volatility model is then constructed. Once again the parameter values from the bivariate system can be used as starting values.

The application of Cholesky decompositions to GARCH models is discussed in Tsay (2005), Chang and Tsay (2010) and Dellaportos and Pourahmadi (2011). This type of model is closely related to factor models; see for example, the discussion of orthogonal GARCH models in Alexander (2001). The advantage of the approach is that the multivariate conditional covariance estimation can be reduced to estimating the $3 \mathrm{~N}$ parameters of univariate GARCH models and a few 'dependence' parameters. The advantage of this approach is that the Cholesky-GARCH models have correlation matrices that are time-varying, and can be more flexible than Bollerslev's (1990) constantcorrelation GARCH models. The main disadvantage of the approach is that the stocks have to be ordered to construct the model. However, given that we already know the relative importance of their shock contributions this is not such a drawback for our current purposes.

The results from the empirical application of these two different approaches and models are presented in the next section.

\section{Empirical results}

\subsection{Data characteristics}

The characteristics of the basic index series, used in our data set and presented in Table 2, suggest the existence of non-normality and fat tails. The Jarque-Bera Lagrange Multiplier test rejects the null hypothesis that the data are normally distributed: the p-values for all indexes above are zero. This is also evident from the skewness and excess kurtosis of the data. In order to estimate the parameters in the GARCH models, the Quasi-Maximum Likelihood Estimator (QMLE) will be used. 


\begin{tabular}{|c|c|c|c|c|c|c|}
\hline & S\&P500 ret & ALL Ord ret & HANGSENG ret & NIKKEI ret & SHANGHAI ret & KOSPI ret \\
\hline \hline Mean & 0.000207 & 0.000260 & 0.000224 & 0.000149 & 0.000220 & 0.000390 \\
\hline Prob. & 0.383365 & 0.403931 & 0.446977 & 0.600047 & 0.474944 & 0.280398 \\
\hline Maximum & 0.1095719593 & 0.0810922093 & 0.1340432034 & 0.1164424712 & 0.0901937935 & 0.2464004135 \\
\hline Minimum & -0.0946951447 & -0.1584914625 & -0.1358877686 & -0.1118564652 & -0.0910142789 & -0.2047944126 \\
\hline Skewness & -0.339884 & -0.995545 & 0.043335 & -0.386103 & -0.272083 & -0.303964 \\
\hline Prob. & 0.000000 & 0.000000 & 0.354947 & 0.000000 & 0.000000 & 0.000000 \\
\hline Excess Kurtosis & 11.898603 & 9.782006 & 10.072437 & 6.134828 & 3.909530 & 20.087461 \\
\hline \hline Prob. & 0.000000 & 0.000000 & 0.000000 & 0.000000 & 0.000000 & 0.000000 \\
\hline Variance & 0.000155 & 0.016900 & 0.000238 & 0.000220 & 0.000259 & 0.000358 \\
\hline Jarque-Bera & 16198.34 & 11364.489773 & 11570.839096 & 4360.088133 & 1776.831001 & 46058.652729 \\
\hline Prob. & 0.000000 & 0.000000 & 0.000000 & 0.000000 & 0.000000 & 0.000000 \\
\hline
\end{tabular}

Table 2: Descriptive statistics

The two returns series are clearly non-normal as reflected in the descriptive statistics reported in Table 2. Plots of the Index return series are shown in Figure 3.

Figure 3: Return Series plots for Australia, US, Japan, Hong Kong, Shanghai and Korea.
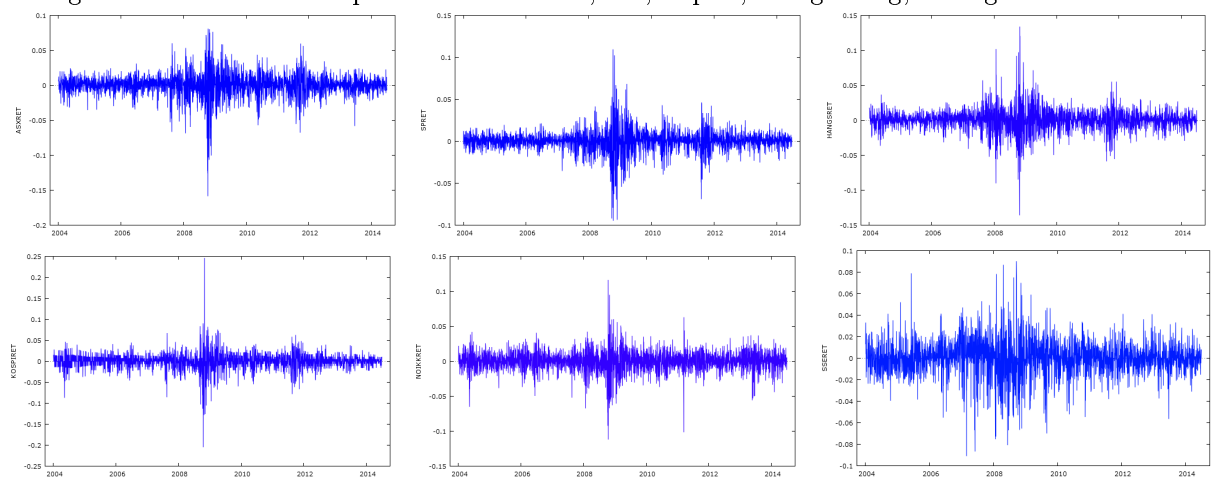

Plots of the Oxford-Man RV estimates, sampled at ten minute intervals within the day, and used as the series for our measures of index volatility are shown in Figure 4. 
Figure 4: Volatility Series plots for Australia, US, Japan, Hong Kong, and Korea.

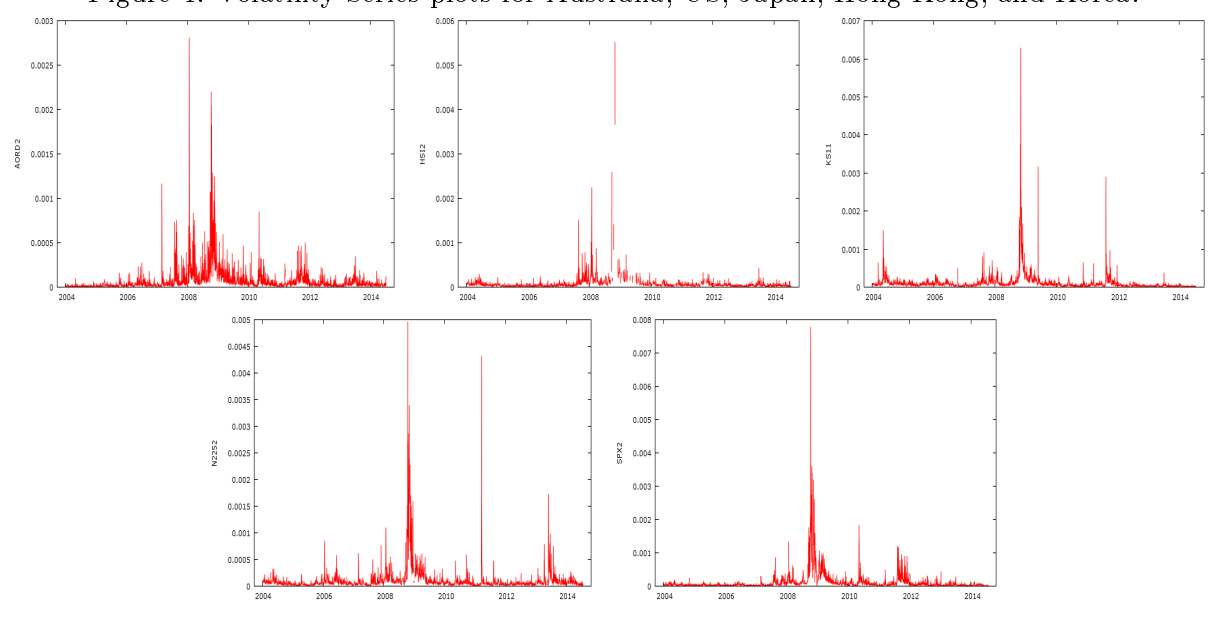

\subsection{Spillover Index Results}

The results of the application of the Spillover index to the return series, and the various decomposition analyses, are shown in Table 3. One of the startling features of Table 3 is the degree of influence on the Australian All Ordinaries returns series exerted by the other equity markets of its major trading partners. Its contribution from others' returns, presented in the extreme right hand column of Table 3 , is the largest at $57 \%$, whilst its contribution to its own return shocks, is the lowest at $42.9 \%$. At the other extreme, the most independent market indices in Table 3, are the Shanghai composite, which explains $96.1 \%$ of the shocks to its own return series, and the S\&P500 Index, which explains $99.6 \%$ of its own return shocks.

In terms of contributions to the behaviour of other markets return series, the least influential is the Korean Kospi, which only contributes $1 \%$, as can be seen in the penultimate row of the column headed by 'Kospi', in Table 3. The most influential market is the US market, which contributes $117 \%$. The Australian market contributes 10\%, more than Japan, which contributes $6 \%$, but less than the Hong Kong contribution at 37\%, and Chinese contribution, via the Shanghai Composite, which contributes $25 \%$. However, the bulk of Chinese influence is on the Hong Kong Index, measured at $13.2 \%$, and the Korean Kospi, recorded at $5.7 \%$.

The two large influences on the Australian All Ordinaries return series, which can be seen by looking across the row labelled 'All Ordinaries' in Table 3, are first and foremost the US market, which contributes $41 \%$ on average, and the Hong Kong market, which contributes $11.7 \%$. The influence of the Shanghai Composite is only small measured at $3.6 \%$. The relative influence of the various markets considered in the analysis can be seen in the bottom row of Table 3 . The most influential is the US market, with a total contribution of $217 \%$, if we include its contribution to its own variance. The next most influential market is the Chinese market, via the Shanghai Composite, with a total contribution measured at $121 \%$, but the bulk of this influence is within it own borders, given that it contributes $13.2 \%$ to Hong Kong return behavior, and the rest largely impacts on the Korean market, which is recorded at $5.7 \%$. There is only a small residual influence on Australia and Japan at $3.6 \%$ and $2.2 \%$ respectively. Table 3 reflects an average of the contributions over the entire sample period. A moving average analysis was also conducted. 
Table 3: Spillover Index variance decomposition of index returns

\begin{tabular}{|c|c|c|c|c|c|c|l|}
\hline & $\begin{array}{c}\text { Shanghai } \\
\text { Composite }\end{array}$ & Hang Seng & All Ordinaries & Nikkei & S\&P500 & Kospi & $\begin{array}{l}\text { Contribution } \\
\text { from others }\end{array}$ \\
\hline \hline Shanghai Composite & 96.1 & 0.0 & 0.2 & 0.5 & 3.1 & 0.1 & 4 \\
\hline Hang Seng & 13.2 & 60.0 & 1.0 & 0.8 & 25.0 & 0.1 & 40 \\
\hline All Ordinaries & 3.6 & 11.7 & 42.9 & 0.4 & 41.0 & 0.4 & 57 \\
\hline Nikkei & 2.2 & 7.9 & 4.3 & 59.6 & 26.0 & 0.1 & 40 \\
\hline S\&P500 & 0.0 & 0.1 & 0.1 & 0.1 & 99.6 & 0.1 & 0 \\
\hline Kospi & 5.7 & 17.6 & 4.5 & 4.2 & 22.3 & 45.8 & 54 \\
\hline Contribution to others & 25 & 37 & 10 & 6 & 117 & 1 & 196 \\
\hline Contribution including own & 121 & 97 & 53 & 65 & 217 & 47 & $32.7 \%$ \\
\hline
\end{tabular}

The rolling 200 period moving average of the contributions are shown in Figure 5.

Figure 5: Moving average analysis of return and volatility spillovers using a 200 day window
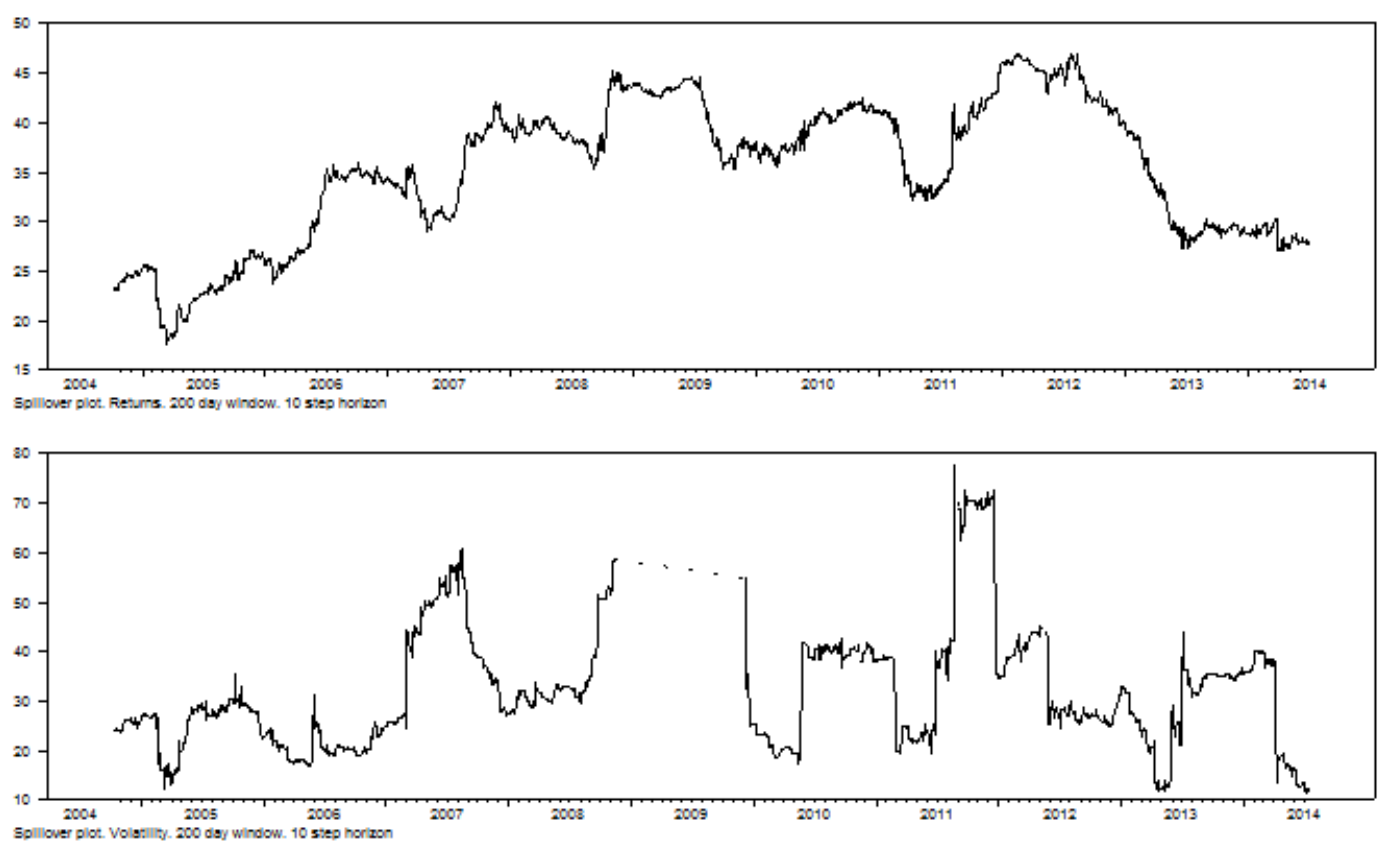

The return spillover effects in the top panel of Figure 5 are smoother than the volatility spillover effects in the bottom panel. The return spillovers peak in 2008-2009 and in 2011-2012. The volatility spillover effects are not as smooth and peak in the middle of 2007, consistent with the onset of the GFC, and then again in late 2008-2009, before reaching an even higher peak in late 2011. The composition of the volatility spillover contributions is shown in Table 4. 
Table 4: Spillover Index variance decomposition of index volatilities

\begin{tabular}{|c|c|c|c|c|c|c|}
\hline & Hang Seng & All Ordinaries & Nikkei & S\&P500 & Kospi & Contribution from others \\
\hline \hline Hang Seng & 60.6 & 2.9 & 3.1 & 33.4 & 0 & 39 \\
\hline All Ordinaries & 6.1 & 57.9 & 4.4 & 31.3 & 0.3 & 42 \\
\hline Nikkei & 1.0 & 1.2 & 93.2 & 4.6 & 0.0 & 7 \\
\hline S\&P500 & 0.4 & 1.3 & 0.4 & 97.3 & 0.6 & 3 \\
\hline Kospi & 1.1 & 1.0 & 1.6 & 10.1 & 86.2 & 14 \\
\hline Contribution to others & 9 & 6 & 9 & 79 & 1 & 105 \\
\hline Contribution including own & 69 & 64 & 103 & 177 & 87 & $21 \%$ \\
\hline
\end{tabular}

Consistent with the evidence on the return series shown in Table 4, the US market is clearly the most dominant, with a small $3 \%$ contribution from other markets in explaining the variance of its own variances, but with a dominant contribution to the others of $79 \%$. The second most independent market is Japan, which has 7\% explained by external shocks. The US has the greatest influence on the Hong Kong market at 33.4\%, closely followed by Australia at $31.3 \%$.

Indeed, Australia is the most dependent market in terms of shocks to its volatility, given that own shocks explain on average $57.9 \%$ of the variances, whilst outside markets explain $42 \%$. The second most influential market on the Australian market volatility is Hong Kong, which explains $2.9 \%$ of Australian volatility. The least influential market is Korea which contributes $1 \%$ of the shocks to the volatility of the other markets, followed in lack of importance by Australia, which contributes $6 \%$.

However, the Choleski decomposition and variance decompositions, as undertaken in the Diebold and Yilmaz (2009) analysis, are influenced by the order in which the variables are placed in the VAR. Diebold and Yilmaz (2012) update their method using a generalized vector autoregressive framework, in which forecast-error variance decompositions are invariant to variable ordering. They exploit the generalized (GIRF) VAR framework of Koop, Pesaran and Potter (1996) and Pesaran and Shin (1998), to construct their improved Spillover metric. In the additional analysis reported in Tables 5 and 6, and in Figure 6, we cross check our analysis applying the GIRF framework as used by Diebold and Yilmaz (2012).

Table 5: Spillover Index GIRF variance decomposition of index returns

\begin{tabular}{|c|c|c|c|c|c|c|c|}
\hline & $\begin{array}{c}\text { Shanghai } \\
\text { Composite }\end{array}$ & Hang Seng & All Ordinaries & Nikkei & S\&P500 & Kospi & $\begin{array}{c}\text { Contribution } \\
\text { from others }\end{array}$ \\
\hline \hline Shanghai Composite & 73.8 & 12.4 & 4.1 & 2.3 & 2.4 & 4.9 & 26 \\
\hline Hang Seng & 8.2 & 45.1 & 11.4 & 6.6 & 15.7 & 13.0 & 55 \\
\hline All Ordinaries & 2.6 & 10.6 & 41.0 & 6.6 & 29.2 & 10.0 & 59 \\
\hline Nikkei & 1.6 & 7.3 & 8.1 & 53.2 & 19.2 & 10.5 & 47 \\
\hline S\&P500 & 0.0 & 0.0 & 0.1 & 0.0 & 99.0 & 0.8 & 1 \\
\hline Kospi & 3.6 & 14.2 & 11.0 & 9.7 & 14.2 & 47.3 & 53 \\
\hline Contribution to others & 16 & 45 & 35 & 25 & 81 & 39 & 240 \\
\hline Contribution including own & 90 & 90 & 76 & 78 & 180 & 87 & $40.1 \%$ \\
\hline
\end{tabular}

The results in Table 5 largely confirm the previous results in Table 3 in terms of shocks to return 
series. Australia is the most influenced by external shocks to its return series, which explain $59 \%$ of its variance, whilst own shocks explain $41 \%$. The most independent and influential market is the US which contributes $81 \%$ of the shocks to other markets but explains $99 \%$ of its own variance. In terms of shocks to its returns, Australia is most influenced by the US at a level of $29.2 \%$, then by Hong Kong at $10.6 \%$, followed by Korea at $10 \%$ and Japan at $6.6 \%$. The least influential series is that of the Shanghai Exchange, which contributes only 2.6\%. China, in the form of the Shanghai Exchange, is the least influential market in terms of the transmission of returns shocks, contributing only $16 \%$, followed by Japan at $25 \%$ and then Australia at 35\%. Hong Kong is the second most influential market in the data set, contibuting $45 \%$ to the variance of returns in other markets.

The ordering of infuence does not correspond with market capitalizations. The NYSE has the largest current capitalisation in the World, followed by NASDAQ and then Japan. Hong Kong is the sixth largest market followed by Shanghai, then the Australian market is ranked fourteenth and the Korean market fifteenth. The surprise, in this context, is the relatively small influence of the Japanese market, event though it is the third largest in the world.

The relative rankings order is confirmed by the GIRF analysis of the variance Spillover Index shown in Table 6.

Table 6: Spillover Index GIRF variance decomposition of index variances

\begin{tabular}{|c|c|c|c|c|c|c|}
\hline & Hang Seng & All Ordinaries & Nikkei & S\&P500 & Kospi & Contribution from others \\
\hline Hang Seng & 64.3 & 1.8 & 3.6 & 27.9 & 2.4 & 36 \\
\hline All Ordinaries & 14.0 & 53.6 & 4.6 & 27.1 & 0.7 & 46 \\
\hline Nikkei & 3.1 & 0.7 & 84.4 & 4.1 & 2.7 & 15 \\
\hline S\&P500 & 7.3 & 1.0 & 0.6 & 87.0 & 4.2 & 13 \\
\hline Kospi & 3.1 & 0.5 & 1.7 & 9.2 & 85.5 & 15 \\
\hline Contribution to others & 29 & 7 & 10 & 68 & 10 & 125 \\
\hline Contribution including own & 94 & 61 & 95 & 155 & 95 & $25 \%$ \\
\hline
\end{tabular}

The GIRF analysis of Spillover variances, shown in Table 6, reveals that Australia is the least independent of all the markets, with own shocks explaining only $53.6 \%$ of its variances. The US market again has the greatest influence, explaining $27.1 \%$ of the variances, followed by the Hong Kong market which explains $14 \%$ of the variances of the variances, and then the Japanese market, which explains $4.6 \%$. In terms of contributions to explanations of the variances in volatility of other markets, the US market dominates, explaining $68 \%$ in total, followed by the Hong Kong market which explains 29\%. The Australian market is the least influential of those considered, and contributes only $7 \%$ to the explanation of the variances of the other markets considered.

A moving average analysis of the GIRF version of the Spillover Index is shown in in Figure 6. 
Figure 6: Moving average analysis of return and volatility GIRF based spillovers using a 200 day window
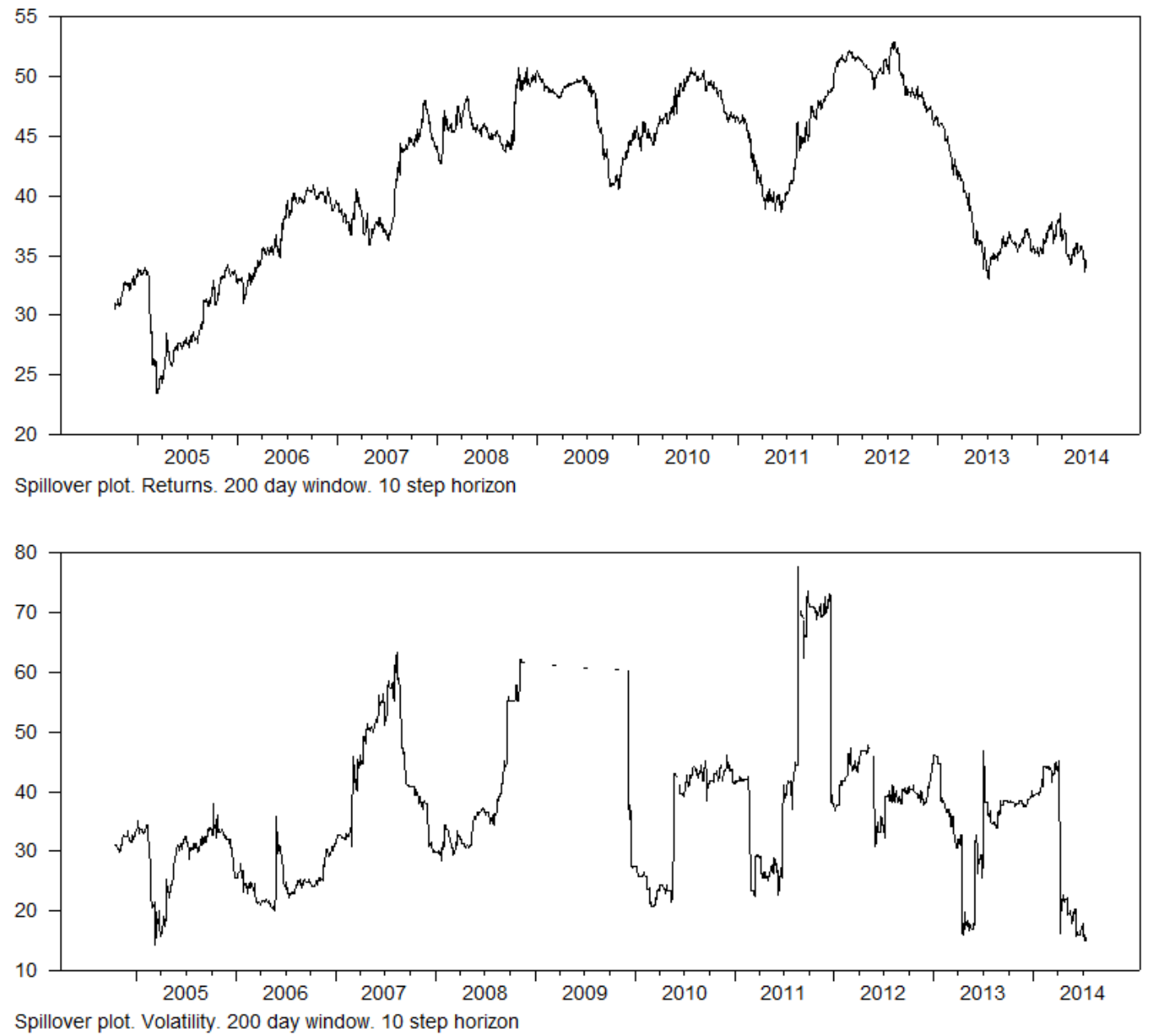

This analysis, using the Diebold and Yilmaz (2009) and (2012) versions of the Spillover Index, confirms that the Australian market is most influenced by the US market, followed by the Hong Kong market. In the subsequent analysis, done withith a GARCH framework, we will concentrate on the contributions of these two markets.

\subsection{Analysis within a GARCH framework}

Before we conducted the GARCH tests, we tested for the existence of ARCH effects in the data sets. The results are shown below in Table 3, and display clear evidence of significant ARCH effects in all of the index series. 


\begin{tabular}{|c|c|c|c|}
\hline Market & Test Statistic (Chi-Square) & $\mathrm{p}$ value & ARCH effect \\
\hline \hline S\&P500 & 977.931 & 0.000000 & Yes \\
\hline ALL ORDINARIES & 441.59 & 0.000000 & Yes \\
\hline HANGSENGRET & 356.648 & 0.000000 & Yes \\
\hline SHANGHAI SE & 101.903 & 0.000000 & Yes \\
\hline NIKKEI & 189.413 & 0.000000 & Yes \\
\hline KOSPI & 258.704 & 0.000000 & Yes \\
\hline
\end{tabular}

Table 7: Test results for ARCH effects

The results in Table 3 mean we can proceed with confidence to the GARCH analysis.

\subsection{Trivariate model based on Cholesky decompositions.}

We adopt a multivariate framework applying Cholesky-GARCH models. We estimate a univariate GARCH model for the US S\&P500 index return series. We then add the Australian All Ordinaries index return series to the system, perform orthogonal transformation on the shock process for the Australian return series, and then build a bivariate volatility model for the system. We then augment the system further, and add in a return series for the Hang Seng Index to capture co-dependencies with China. The system then becomes a trivariate one.The parameter estimates for the GARCH model of the US return series are used as the commencement values in the bivariate estimation, and the estimation is augmented in a stepwise fashion, first adding in the Australian index and then the Hang Seng index. The components of the return series are ordered as $r_{t}=\left(S P R E T L_{t}, A S X R E T_{t}, H A N G S R E T_{t}\right)$. The sample means, standard errors and correlation matrix of the data are:

$$
\hat{\mu}=\left[\begin{array}{l}
0.00021 \\
0.00026 \\
0.00022
\end{array}\right] \cdot\left[\begin{array}{l}
\hat{\sigma}_{1} \\
\hat{\sigma}_{2} \\
\hat{\sigma}_{3}
\end{array}\right]=\left[\begin{array}{l}
0.0124 \\
0.0163 \\
0.0154
\end{array}\right] \cdot \hat{\rho}=\left[\begin{array}{ccc}
1.00 & 0.25095 & 0.22933 \\
0.25095 & 1.00 & 0.65536 \\
0.22933 & 0.65536 & 1.00
\end{array}\right] .
$$

Tests of serial correlation in the three return series applying Ljung-Box statistics we obtain $Q_{3}(1)=1205.43335, Q_{3}(4)=1280.38447$, and $Q_{3}(8)=1440.30046$, and all are highly significant with $\mathrm{p}$ values close to zero in terms of chi-squared distributions with 9,36 , and 72 degrees of freedom respectively. There is also significant evidence of dependencies in cross-correlation matrices of returns up to six lags.

The initial estimate of the GARCH model for the US S\&P 500 index return series yields the mean equation $r_{1 t}=0.00056169(0.00009224)+-0.0577 r_{t-1}(0.00531397)+a_{1 t}$ with significance levels in parentheses. The GARCH equation for the US S\&P 500 index return series is $h_{1 t}=$ $0.00000158(0.000)+0.0862 \alpha(0.000)+0.8987 h_{1, t-1}(0.000)+e_{1 t}$. The system is then augmented by adding in the Australian S\&P 200 index returns series. The model is re-estimated and finally the Hang Seng Index return series is added to the system. Our final model is estimated as shown in Table 6.

Our final mean equations are shown below:

$$
\begin{gathered}
r_{U S R E T L, t}=C_{1}-P_{3} U S R E T L_{t-1}+a_{1 t} \\
r_{A U S R E T, t}=C_{2}+P_{21} U S R E T L_{t-1}-P_{22} \text { AUSRET } T_{t-1}+a_{2 t} \\
r_{H A N G S E N G R E T, t}=C_{3}+P_{31} \text { USRETL }_{t-1}-P_{33} \text { HANGSENGRET }_{t-1}+a_{3 t}
\end{gathered}
$$


It can be seen in Table 6 that all coefficients on lagged returns in the US market are significant in all three mean equations and the lagged terms on the Australian and Chinese markets are also significant in the mean equations. Manipulation of the above equations provides the three residual series $a_{1 t}, a_{2 t}, a_{3 t}$.

The three dimensional time-varying volatility model can be obtained as follows:

$$
\begin{gathered}
g_{11, t}=A_{0}+A_{1} b_{1, t-1}^{2}+A_{2} g_{11, t-1} \\
q_{21, t}=T_{0}+T_{1} q_{21, t-1}-T_{2} a_{2, t-1} \\
g_{22, t}=B_{0}+B_{1} b_{2, t-1}^{2}+B_{2} g_{22, t-1} \\
q_{31, t}=U_{0}+U_{1} q_{31, t-1}+U_{2} a_{3, t-1} \\
q_{32, t}=W_{0}+W_{1} q_{31, t-1}+W_{2} a_{2, t-1} \\
g_{33, t}=D_{0}+D_{1} b_{3, t-1}^{2}+D_{2} g_{33, t-1}+D_{5} g_{22, t-1}
\end{gathered}
$$

Where $b_{1 t}=a_{1 t}, b_{2 t}=a_{2 t}-q_{21, t} b_{1 t}, b_{3, t}=a_{3, t}-q_{31, t} b_{1 t,}-q_{32, t} b_{2 t}$.

It can be seen in Table 6 that all terms except $C_{3}, D_{0}, T_{2}, U_{0}, W_{0}, W_{1}$, and $W_{2}$, are significant.

\begin{tabular}{|c|c|c|c|}
\hline Variable & Coefficient & t statistic & significance \\
\hline \hline$C_{1}$ & 0.000582744 & 3.79417 & 0.00014814 \\
\hline$P_{3}$ & -0.058987645 & -2.62631 & 0.00863169 \\
\hline$C_{2}$ & 0.000334982 & 1.69754 & 0.08959431 \\
\hline$P_{21}$ & 0.707612282 & 32.85036 & 0.00000 \\
\hline$P_{22}$ & -0.097391253 & -6.61486 & 0.00000 \\
\hline$C_{3}$ & 0.000208681 & 1.08434 & 0.27821190 \\
\hline$P_{31}$ & 0.578358126 & 30.06355 & 0.0000000 \\
\hline$P_{33}$ & -0.074583220 & -4.83857 & 0.00000131 \\
\hline$A_{0}$ & 0.000001584 & 6.87642 & 0.00000000 \\
\hline$A_{1}$ & 0.086311860 & 11.29579 & 0.00000000 \\
\hline$A_{2}$ & 0.898607050 & 102.85983 & 0.00000000 \\
\hline$B_{0}$ & 0.000002529 & 4.30673 & 0.0000166 \\
\hline$B_{1}$ & 0.081139161 & 9.36304 & 0.00000000 \\
\hline$B_{2}$ & 0.900419623 & 81.19797 & 0.00000000 \\
\hline$D_{0}$ & 0.000000013 & 0.03799 & 0.96969907 \\
\hline$D_{1}$ & 0.037988239 & 6.29223 & 0.00000000 \\
\hline$D_{2}$ & 0.930500532 & 92.98412 & 0.00000000 \\
\hline$D_{5}$ & 0.024232739 & 3.85372 & 0.00011634 \\
\hline$T_{0}$ & 0.000530013 & 3.74068 & 0.00018352 \\
\hline$T_{1}$ & 0.999027780 & 2380.65243 & 0.00000000 \\
\hline$T_{2}$ & -0.034777026 & -0.29552 & 0.76759547 \\
\hline$U_{0}$ & 0.007778653 & 1.28076 & 0.20027768 \\
\hline$U_{1}$ & 0.886814379 & 10.98282 & 0.00000000 \\
\hline$U_{2}$ & -1.557344857 & -2.67711 & 0.00742597 \\
\hline$W_{0}$ & 0.123906856 & 0.56884 & 0.56946643 \\
\hline$W_{1}$ & 0.723415309 & 1.49166 & 0.13578952 \\
\hline$W_{2}$ & -0.525155895 & -0.93358 & 0.35051968 \\
\hline & & & \\
\hline
\end{tabular}

Table 8: Tri-variate GARCH model based on Cholesky decompositions, US, Australia, and China 
The model diagnostics appear to be reasonably satisfactory, the Ljung-Box Q statistics for the three sets of residual series are insignificant for series RES1, RES2 and RES3 for 4, 8 and 12 lags respectively. There is evidence of an increased degree of correlation between the markets during and after the financial crisis, as shown in Figure 6 below.

Figure 7: Time-varying correlations between the USA, Australia and China index series

(a) S\&P 500 index and Australian All Ordinaries

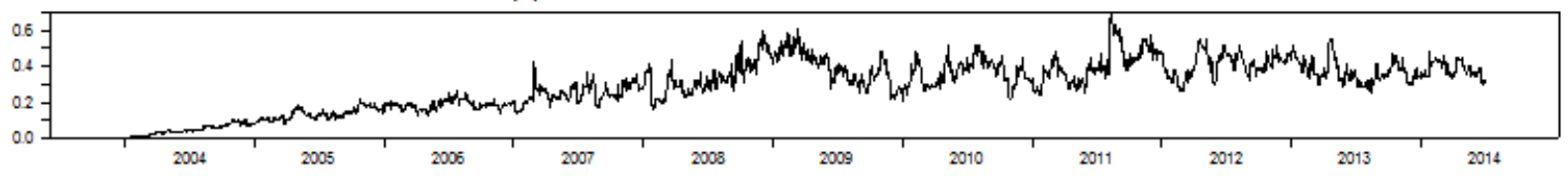

(b) S\&P 500 index and HANGSENG index

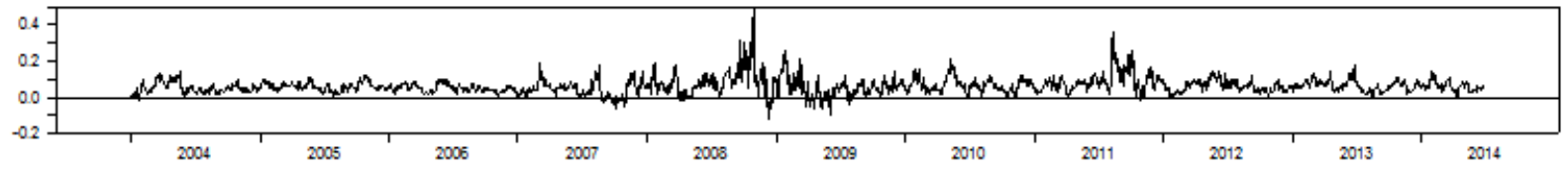

(a) Australian All Ordinaries and HANGSENG Index

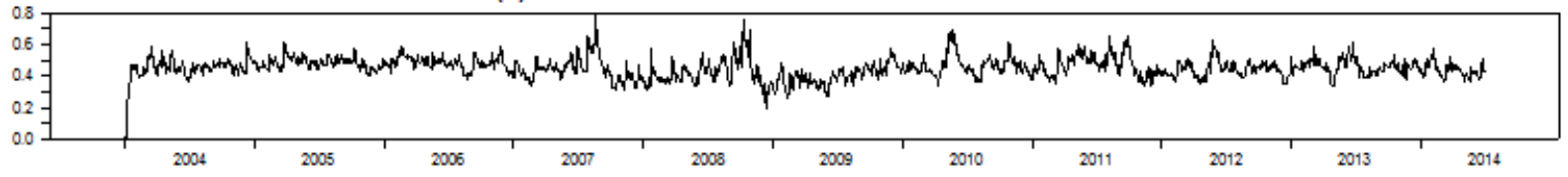

Figure Time-varying correlation coefficients

The estimates in Table 6, of time varying correlations, augment the insights of the moving window estimates in Figure 5, of return and volatility spillovers across all three markets. There are peaks in correlations between the S\&P500 and All Ordinaries Index, after the onset of the GFC, in 2008-2009, and then again in 2011. There is a low level of correlation between the S\&P500 and the Hang Seng Index, but evidence of peaks in late 2008 and in 2011. There is a consistent and relatively high level of correlation between the Australian All Ordinaries and the Hang Seng Index, and evidence of peaks in late 2007, late 2008, 2010 and 2011.

\section{Conclusion}

This paper features an analysis of the impact of the GFC on Australian Index returns, and the transmission of volatility, from Australia's main trading partners to Australia, during this period. The Volatility Spillover Index analysis shows that the key influences on Australia, in terms of both shocks to returns and to volatility, are the US and Hong Kong markets. Even though the Australian banking system faired well during the GFC, there is strong evidence of the transmission of volatility from the US to Australia, and to China, as reflected in the behaviour of the Hang Seng index. However, there is little evidence of impact on Australian markets from China, as represented by the Shanghai market. 
The trivariate Cholesky-GARCH model also shows strong influence from US shocks on both Australia and China, though reduced influence from China in the system. All correlations between the the three index series appear to rise post GFC.

The problems for investors in times of financial crises appear to be exacerbated by the transmission of shocks; even countries that faired relatively well, such as Australia, were significantly impacted. There is also less scope for risk diversification, as correlations appear to rise in times of financial distress. Allen and Powell (2012) provide corroboratory evidence of the rise in riskiness of the Australian banks during the period of the GFC. Allen and Faff (2012), survey some aspects of the general impact of the GFC on Australian markets.

There is no obvious and straightforward interpretation of why some markets have more influence on the Australian market than others. It is not a simple matter of market capitalisation, given that Japan ranks third in the World in terms of market capitalisation, and is ranked second as a trading partner to Australia, and yet has a relatively minor influence on the Australian equity market. Hong Kong has a much greater impact, yet is only sixth in the world in market capitalisation terms, and is not as important as Japan, in trade terms. This issue merits further exploration. 
[1] Allen, D.E. and R. Faff, 2012, The Global Financial Crisis: some attributes and responses, Accounting and Finance, Special Issue: Global Financial Crisis, 52, 1, 1-7.

[2] Allen, D. E. and R.J. Powell, 2012, The Fluctuating Default Risk of Australian Banks, Australian Journal of Management, 37(2), 297-325.

[3] Alexander, C. 2001, Market Models: A Guide to Financial Data Analysis, Wiley, New York.

[4] Barth, J.R., R. Koepp, and Z. Zhou, 2004, Banking Reform in China: Catalyzing the Nation's Financial Future, (2004) Available at SSRN: http://papers.ssrn.com/sol3/papers.cfm?abstract_id $=548405$.

[5] Bauwens, L., S. Laurent, and J.V.K. Rombouts, 2003, Multivariate GARCH models: A survey, CORE Discussion Paper No. 2003/31. Available at SSRN: http://ssrn.com/abstract $=411062$.

[6] Bollerslev, T., 1986, Generalized autoregressive conditional heteroscedasticity, Journal of Econometrics, 31, 307-327.

[7] Bollerslev, T., 1990, Modelling the coherence in short-run nominal exchange rates: A multivariate generalized ARCH model, Review of Economics and Statistics, 72, 498505.

[8] Chang, C., and R.S. Tsay, 2010, Estimation of covariance matrix via sparse Cholesky factor with Lasso. J. Stat. Plan. Inference, 40, 3858 -3873.

[9] Cheng, H. and J. Glascock, 2005, Dynamic Linkages Between the Greater China Economic Area Stock Markets-Mainland China, Hong Kong, and Taiwan, Review of Quantitative Finance and Accounting, 24, 343-357.

[10] Cheung, W., S. Fung, and S. Tsai, 2010, Global capital market interdependence and spillover effect of credit risk: evidence from the 2007-2009 global financial crisis, $A p$ plied Financial Economics, 20, 85-103.

[11] Dellaportos, P., M. Pourahmadi, 2012, Cholesky-GARCH models with applications to finance, Statistical Computing, 22, 849-855.

[12] Didier, T., I. Love, and M. Peria, 2012, What explains comovement in stock market returns during the 2007-2008 crisis? International Journal of Finance and Economics, $17,182-202$.

[13] Doan, T., 2010, RATS programs to replicate Diebold and Yilmaz EJ 2009 spillover calculations, Statistical Software Components from Boston College Department of Economics.

[14] Diebold, F, X., and K. Yilmaz, 2009, Measuring financial asset return and volatility spillovers, with application to global equity markets, The Economic Journal, 158-171.

[15] Diebold, F. X., and K. Yilmaz, 2012, Better to give than to receive: Predictive directional measurement of volatility spillovers, International Journal of Forecasting, vol. $28(1), 57-66$. 
[16] Dooley M., and M. Hutchison, 2009, Transmission of the U.S. subprime crisis to emerging markets: Evidence on the decoupling-recoupling hypothesis, Journal of International Money and Finance, 28, 1331-1349

[17] Engle, R.F., 1982, Autoregressive conditional heteroskedasticity with estimates of the variance of United Kingdom inflation, Econometrica, 50, 987-1008.

[18] Engle, R. F., 2001, GARCH 101: An Introduction to the Use of Arch/Garch Models in Applied Econometrics, Journal of Economic Perspectives,15, 4, 157-168.

[19] Engle, R.F., T. Ito, T. and W-L. Lin, 1990, Meteor showers or heat waves? Heteroskedastic intra-daily volatility in the foreign exchange market, Econometrica, 58(3) (May), pp. 525-42.

[20] Engle, R.F., V.K. Ng, 1993, Time-varying volatility and the dynamic behavior of the term structure, Journal of Money, Credit and Banking, 25 (3), 336-349.

[21] Evans, M.D.D., and V. V. Hnatkovska, 2014, International capital flows, returns and world financial integration, Journal of International Economics, 92, (1), 14-33

[22] Gokcan, S., 2000, Forecasting volatility of emerging stock markets: linear versus nonlinear GARCH models, Journal of Forecasting, 19, 499-504.

[23] Gorton, G., 2010, Slapped by the Invisible Hand: The Panic of 2007, Oxford University Press, Oxford.

[24] Greenspan, A., 2010, "The Crisis", Brookings Papers on Economic Activity, Spring.

[25] Fidrmuc, J., and L. Korhonen, 2010, The impact of the global financial crisis on business cycles in Asian emerging economies, Journal of Asian Economics, 21, 293303.

[26] Glosten, L.R., R. Jagannathan, D. Runkle, 1993, On the relation between the expected value and the volatility of the nominal excess return on stocks, Journal of Finance, 48, 1779-1801.

[27] Hamao, Y., R.W. Masulis, and V. Ng, 1990, Correlations in price changes and volatility across international stock markets, Review of Financial Studies, 3(2), 281-307.

[28] Hamilton, J.D., 1989, A New Approach to the Economic Analysis of Nonstationary Time Series and the Business Cycle, Econometrica, 57, 357-384.

[29] Harris, R.D.F., E. Stoja, J. Tucker, 2007, A simplified approach to modeling the comovement of asset returns, Journal of Futures Markets, 27(6), 575-598.

[30] Harvey, C.R., A.R. Siddique, 1999, Autoregressive conditional skewness, Fuqua School of Business Working Paper No. 9604, Available at SSRN: http://ssrn.com/abstract $=61332$ or doi:10.2139/ssrn.61332.

[31] Huang B.-N., C-W.Yang, J.W.-S. Hu, 2000, Causality and cointegration of stock markets among the United States, Japan and the South China Growth Triangle, International Review of Financial Analysis, 9, 281-297. 
[32] Johansson, A.C., and C. Ljungwall, 2009, Spillover effects among the Greater China stock markets, World Development, 37, 4, 839-851.

[33] Koop, G., M.H. Pesaran, and S.M. Potter, 1996, Impulse Response Analysis in NonLinear Multivariate Models, Journal of Econometrics, 74, 119-147.

[34] Kotkatvuori-Örnberg, J., J. Nikkinen, and J. Äijö, 2013, Stock market correlations during the financial crisis of 2008-2009: Evidence from 50 equity markets, International Review of Financial Analysis,28, 70-78.

[35] Lima, L.R., B.P. Neri, 2007, Comparing value-at-risk methodologies, Brazilian Review of Econometrics, 27(1), 1-25.

[36] Ling, S., and M. McAleer, 2003, Asymptotic theory for a vector ARMA-GARCH model, Econometric Theory, 19 (2), 280-310.

[37] McAleer, M., 2005, Automated inference and learning in modeling financial volatility, Econometric Theory, 21, 232-261.

[38] McAleer, M., F. Chan, S. Hoti, and O. Lieberman, 2008, Generalized autoregressive conditional correlation, Econometric Theory, 24(6), 1554-1583.

[39] McAleer, M., F. Chan, and D. Marinova, 2007, An econometric analysis of asymmetric volatility: Theory and application to patents, Journal of Econometrics, 139, 259-284.

[40] McAleer, M., S. Hoti, and F. Chan, 2009, Structure and asymptotic theory for multivariate asymmetric conditional volatility, Econometric Reviews, 28(5), 422-440.

[41] Manera, M., M. McAleer, and M. Grasso, 2006, Modelling time-varying conditional correlations in the volatility of Tapis oil spot and forward returns, Applied Financial Economics, 16(7), 525-533.

[42] Manganelli, S., and R.F. Engle, 2001, Value at risk models in finance, ECB Working Paper No. 75 Available at SSRN: http://ssrn.com/abstract $=356220$

[43] Min, H. and S. Hwang, 2012, Dynamic correlation analysis of US financial crisis and contagion: evidence from four OECD countries, Applied Financial Economics, 22, 2063-2074.

[44] Moon G.H., and W.C. Yu, 2010, Volatility spillovers between the US and the China stock markets: Structural break test with symmetric and asymmetric GARCH approaches, Glob. Econ. Review, 39(2), 129-149.

[45] Mun, M. and R. Brooks, 2012, The roles of news and volatility in stock market correlations during the global financial crisis, Emerging Markets Review, 13, 1-7.

[46] Nelson, D.B., 1991, Conditional heteroskedasticity in asset returns: A new approach, Econometrica, 59(2), 347-370.

[47] Pesaran, M.H. and Y. Shin, 1998, "Generalized Impulse Response Analysis in Linear Multivariate Models," Economics Letters, 58, 17-29. 
[48] So, M.K., and A.S.L.Tsui, 2009, Dynamic modeling of tail risk: Applications to China, Hong Kong and other Asian markets, Asia-Pacific Financial Markets,16, 183-210.

[49] Tsay, R., 2005, Analysis of Financial Time Series, 3rd ed.Wiley, New York.

[50] Yeh Y.-H., T-S, Lee, 2000, The interaction and volatility asymmetry of unexpected returns in the greater China stock markets, Global Finance Journal, 11, 129-149. 